\title{
Renal-targeting triptolide-glucosamine conjugate exhibits lower toxicity and superior efficacy in attenuation of ischemia/reperfusion renal injury in rats
}

\author{
Yu FU, Qing LIN, Tao GONG, Xun SUN, Zhi-rong ZHANG* \\ Key Laboratory of Drug Targeting and Drug Delivery Systems, Ministry of Education, West China School of Pharmacy, Sichuan \\ University, Chengdu 610041, China
}

\begin{abstract}
Aim: We previously reported a novel triptolide (TP)-glucosamine conjugate (TPG) that specifically accumulated in kidneys and protected renal function from acute ischemia/reperfusion (I/R) injury in rats. In this study we further examined the molecular mechanisms underlying the renoprotective action of TPG.

Methods: The renal-targeting of TPG was investigated in a human proximal renal tubular epithelial cell line (HK-2) by measuring cell uptake of TP or TPG. The effects of TP or TPG on cell cycle distribution and apoptosis rate of HK-2 cells were assessed, and the activities of caspase-3 and caspase- 9 were also measured. SD rats were subjected to bilateral renal ischemia by temporarily clamping both renal pedicles. The rats were administered TP $\left(4.17 \mu \mathrm{mol} \cdot \mathrm{kg}^{-1} \cdot \mathrm{d}^{-1}\right.$, iv $)$ or TPG $\left(4.17 \mu \mathrm{mol}^{\prime} \mathrm{kg}^{-1} \cdot \mathrm{d}^{-1}\right.$, iv $)$ for $3 \mathrm{~d}$ before the renal surgery. The kidneys were harvested after $24 \mathrm{~h}$ of recovery from the surgery. The levels of oxidative stress, proinflammatory cytokines, chemotactic cytokines and intracellular adhesion molecules in kidneys were examined.

Results: The uptake of TPG in HK-2 cells was 2-3 times higher than that of TP at the concentrations tested. Furthermore, TPG targeting the proximal tubules was mediated through interactions with megalin receptors. TP (40-160 nmol/L) concentrationdependently increased $\mathrm{G}_{2} / \mathrm{M}$ arrest, apoptosis and caspase-3/caspase-9 activity in HK-2 cells, whereas the same concentrations of TPG did not show those features when compared with the control group. In I/R-treated rats, TPG administration caused more robust down-regulation of proinflammatory cytokines (TNF- $\alpha$, IL-6, IL-1, TGF- $\beta$ ) and chemotactic cytokines (MCP-1) in the kidneys compared with TP administration, suggesting the inhibition of the proliferation and accumulation of lymphocytes. And TPG administration also caused more prominent inhibition on the levels of oxidative stress and intracellular adhesion molecules in the kidneys, compared with TP administration.

Conclusion: The renal-targeting TPG is more effective and less toxic than TP, in amelioration of I/R-induced rat renal injury, which may provide a new avenue for the treatment of acute kidney injury.
\end{abstract}

Keywords: triptolide; triptolide-glucosamine conjugate; acute kidney injury; ischemia/reperfusion; renal targeting; $\mathrm{G}_{2} / \mathrm{M}_{\text {phase }}$ arrest; apoptosis; oxidative stress; proinflammatory cytokines; renoprotection

Acta Pharmacologica Sinica (2016) 37: 1467-1480; doi: 10.1038/aps.2016.44; published online 11 Jul 2016

\section{Introduction}

Renal ischemia/reperfusion (I/R) injury, resulting in aberrant incomplete repair and persistent tubule interstitial inflammation, is a tremendous challenge during renal organ transplantation $^{[1]}$. I/R injury is also one of the major causes of acute renal failure $(\mathrm{ARF})^{[2-4]}$, which is associated with high mortality and morbidity in clinic. Although the subsequent reperfusion

\footnotetext{
${ }^{*}$ To whom correspondence should be addressed.

E-mail zrzzl@vip.sina.com

Received 2016-01-18 Accepted 2016-04-21
}

is essential for the survival of the ischemic tissues, it might inevitably enhance a robust inflammatory process engaging both innate and adaptive immune responses ${ }^{[5,6]}$. Therefore, this reperfusion would further mediate long-term structural changes including interstitial apoptosis and fibrosis ${ }^{[7,8]}$. The pathogenesis of inflammation in I/ R injury is multifactorial and complex ${ }^{[9,10]}$. The process involves a set of consequently produced biomarkers, such as proinflammatory cytokines, leukocyte chemotactic molecules and interstitial macrophage infiltration ${ }^{[11]}$.

Since cells of the proximal tubules are the key sites of 
injury caused by immunological, infectious, metabolic, toxic, mechanical stretch and ischemic insults ${ }^{[11,12]}$, they are thought to be suitable targets for drug delivery systems in the treatment of renal injury of multiple causes. Low molecular weight proteins, peptides, antibody fragments and different polymer systems have been studied extensively as renal carrier systems for the intracellular delivery of therapeutic drugs into the proximal tubular cells ${ }^{[13]}$. In addition to macromolecular carriers, there are other strategies to achieve this goal ${ }^{[14]}$. In the previous work, our group identified a novel triptolide (TP)glucosamine conjugate (TPG) (Figure 1) that could selectively accumulate in the kidneys of rats ${ }^{[15]}$. TPG showed a promising renal targeting, however, the mechanism of TPG remains unknown.
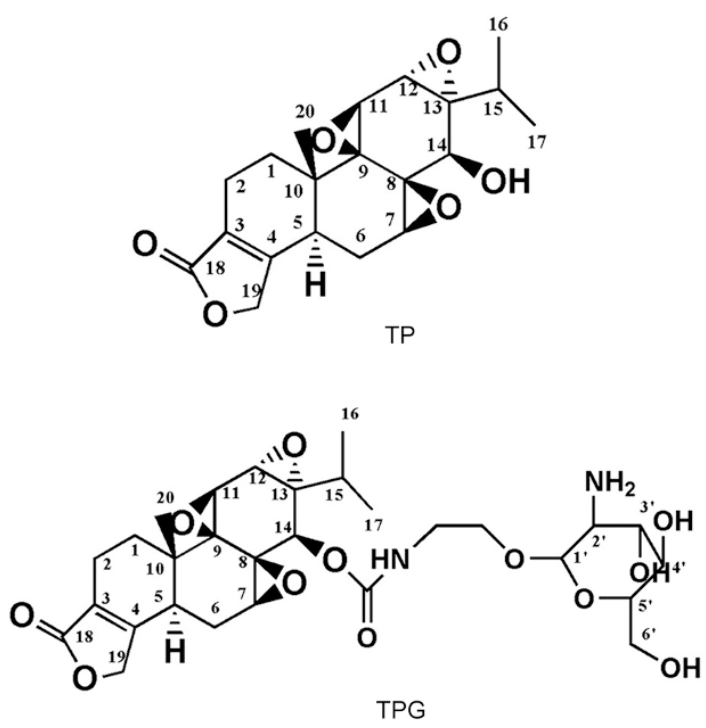

Figure 1. The chemical structure of triptolide (TP) and triptolide-glucosamine conjugate (TPG).

Moreover, compared with TP, TPG efficiently ameliorated potential multi-organ toxicity and substantially reduced acute renal I/ $\mathrm{R}$ injury in rats. TP, a biologically active natural product extracted from the root of the Chinese herb Tripterygium wilfordii, possesses multiple pharmacological activities including anti-rheumatism, anti-inflammatory, anti-tumor and neuroprotective properties ${ }^{[16-18]}$. However, the wide use of TP in clinical practice is limited because of its multi-organ toxicity and narrow therapeutic window. It appeared that TPG obtained promising immunosuppressive and anti-inflammatory activities derived from TP while ameliorating its toxicity $^{[15]}$. Therefore, there is an urgent need to gain mechanistic insight into how TPG is superior to TP in the attenuation of $\mathrm{I} / \mathrm{R}$ injury in rats.

Given the previous observations, TPG should be a promising therapeutic drug for acute renal failure, exerting its protection in kidneys within $24 \mathrm{~h}$ after I/R. In the current study, we first investigated the mechanism of how TPG could specifically target to tubular epithelial cells and effectively ameliorate $\mathrm{I} / \mathrm{R}$ injury in rats, further laying the foundation for a potential route that could be exploited therapeutically.

\section{Materials and methods Chemical reagents}

$\mathrm{TP}$ (purity $\geq 98.0 \%$ ) was obtained from the Chengdu Xiyu Institute of Science (Chengdu, China). TPG was synthesized and purified as previously described ${ }^{[15]}$. Gentamicin was obtained from Henan Runhong Pharmaceutical Co Ltd (He-nan, China). Methanol (chromatography grade) was purchased from Kemiou (Tianjing, China). Watsons distilled water was used as the water phase in the LC-MS/MS system. Chloral hydrate was purchased from Aladdin (USA). All other chemicals and reagents were of analytical grade and were obtained commercially.

\section{Cell culture}

HK-2 cells (a human proximal renal tubular epithelial cell line) were obtained from the Chinese National Cell Line Service (Shanghai, China) and developed in our laboratory. These cells were cultured in DMEM (Dulbecco's modified Eagle's medium) with high glucose (HyClone, USA) supplemented with $10 \%$ fetal calf serum (Gibco, USA), $1 \%(v / v)$ penicillinstreptomycin (10000 units/mL penicillin; $10000 \mu \mathrm{g} / \mathrm{mL}$ streptomycin). L929 cells (a mouse fibroblast cell line) were obtained from the Chinese National Cell Line Service (Shanghai, China) and developed in our laboratory. These cells were cultured in RPMI-1640 (HyClone, USA) supplemented with $10 \%$ fetal calf serum (Gibco, USA), 1\% ( $/ v)$ penicillinstreptomycin $(10000$ units/mL penicillin; $10000 \mu \mathrm{g} / \mathrm{mL}$ streptomycin). The cells were maintained at $37^{\circ} \mathrm{C}$ in a humidified atmosphere containing $5 \% \mathrm{CO}_{2}$ and $95 \% \mathrm{O}_{2}$, and the culture medium was changed every other day. The passage number of both cells was kept within 20-25 for all experiments.

\section{Cell uptake study}

HK-2 or L929 cells were seeded at a density of $5 \times 10^{5}$ cells/dish in NEST (Wuxi, China) culture capsules (diameter of $100 \mathrm{~mm}$ ) and were cultured as described above. The uptake assay was studied in cells during their exponential growth phase. Each value obtained in this section was an average of quintuplicate measurements.

\section{Time course of the cellular uptake}

HK-2 cells were exposed to TPG or TP diluted into $2 \mathrm{~mL}$ serum-free DMEM media at a final concentration of 2.5 $\mathrm{nmol} / \mathrm{mL}$ for $0.25,0.5,1,2$ and $4 \mathrm{~h}$ at $37^{\circ} \mathrm{C}$. After the specified time interval, the drug-containing media were removed. The cells were rinsed three times with ice-cold PBS (phosphate buffer saline) to remove the residual drugs and then lysed by three repeated freeze-thaw cycles to release the intracellular drugs. Afterwards, the ruptured cell suspension was collected for the determination of the intracellular concentration of drugs. The sample preparation and LC-MS/MS (liquid 
chromatography-tandem mass spectrometry) assays were performed as previously described ${ }^{[15]}$. Cell uptake was expressed as the amount (nmol) of TP or TPG associated with a unit weight (mg) of cellular protein. The protein content of the cell lysate was estimated in parallel wells using the Pierce BCA protein assay reagent kit (Pierce, USA) with bovine serum albumin as the standard.

\section{The effect of concentration on cellular uptake}

HK-2 cells were exposed to TPG or TP diluted into $2 \mathrm{~mL}$ serum-free DMEM at increasing concentrations of 0.2, 0.5, 1.0, 2.5 and $5.0 \mathrm{nmol} / \mathrm{mL}$ for $2 \mathrm{~h}$ at $37^{\circ} \mathrm{C}$. The post-treatment was performed as described in the section Time course of cellular uptake.

\section{The effect of temperature on cellular uptake}

HK-2 cells were incubated with TPG or TP diluted into $2 \mathrm{~mL}$ serum-free DMEM at a final concentration of $2.5 \mathrm{nmol} / \mathrm{mL}$ for $2 \mathrm{~h}$ at the temperature of $4{ }^{\circ} \mathrm{C}$ or $37^{\circ} \mathrm{C}$. The post-treatment was performed as described in the section Time course of cellular uptake.

\section{The effect of the different cell lines on cellular uptake}

HK-2 cells and L929 cells were incubated with TPG or TP diluted into $2 \mathrm{~mL}$ serum-free DMEM or RPMI-1640 at a final concentration of $2.5 \mathrm{nmol} / \mathrm{mL}$ for $2 \mathrm{~h}$ at $37^{\circ} \mathrm{C}$. The post-treatment was performed as described in the section Time course of cellular uptake.

\section{The effect of the megalin receptor inhibitor on cellular uptake}

HK-2 cells were incubated with TPG or TP diluted into $2 \mathrm{~mL}$ serum-free DMEM at a final concentration of $2.5 \mathrm{nmol} / \mathrm{mL}$ containing $4 \mathrm{mg} / \mathrm{mL}$ gentamicin or $1 \mathrm{mmol} / \mathrm{L}$ EDTA for $2 \mathrm{~h}$ at $37^{\circ} \mathrm{C}$. The post-treatment was performed as described in the section Time course of cellular uptake.

\section{Cell cycle distribution analysis}

HK-2 cell cycle distribution was determined by DNA staining with PI (propidium iodide) (Sigma). Briefly, when the HK-2 cells reached $40 \%-50 \%$ confluence, they were incubated with TPG or TP at increasing concentrations of $0,40,80$ and 160 $\mathrm{nmol} / \mathrm{L}$ for $24 \mathrm{~h}$ at $37^{\circ} \mathrm{C}$. Then, the cells were washed in PBS and fixed in $70 \%$ ice-cold ethanol for $4 \mathrm{~h}$. After that, the cells were collected and incubated in PBS containing $50 \mu \mathrm{g} / \mathrm{mL}$ PI, $0.1 \mathrm{mg} / \mathrm{mL}$ RNase and $1 \%$ Triton $\mathrm{X}-100$ for $30 \mathrm{~min}$ at $37^{\circ} \mathrm{C}$. Finally, all samples were run into a flow cytometer system (Cytomics FC 500, Beckman Coulter, USA) to determine the level of DNA content. Each value obtained in this section was an average of triplicate measurements.

\section{Cell apoptosis array}

HK-2 cell apoptosis was assessed by a commercial Annexin VFITC/PI Kit (Catalog No.KGA107, KeyGEN BioTECH, Nanjing, China). Briefly, when the HK-2 cells reached $40 \%-50 \%$ confluence, they were incubated with TPG or TP at increasing concentrations of $0,40,80$ or $160 \mathrm{nmol} / \mathrm{L}$ for $24 \mathrm{~h}$ at $37^{\circ} \mathrm{C}$.
Then, the HK-2 cells were harvested and incubated with a mixture of annexin V-FITC and propidium iodide for $30 \mathrm{~min}$ in the dark and then measured by flow cytometry (Cytomics FC 500, Beckman Coulter, USA). Each value obtained in this section was an average of triplicate measurements.

\section{Caspase- 3 and caspase- 9 assay}

Caspase- 3 and caspase- 9 activity assays in HK-2 cells were tested by a commercial Caspase-3 Assay Kit (Catalog No C1116, Beyotime, China) or a Caspase-9 Assay Kit (Catalog No C1158, Beyotime, China) according to the manufacturer's instructions. Briefly, after the administration of TP or TPG at increasing concentrations of $0,40,80$ or $160 \mathrm{nmol} / \mathrm{L}$ for $24 \mathrm{~h}$ at $37^{\circ} \mathrm{C}, \mathrm{HK}-2$ cells were harvested. Then, the cells were suspended in $50 \mu \mathrm{L}$ of ice-cold cell lysis buffer and incubated for $15 \mathrm{~min}$ on ice. After centrifugation at $16000 \times \mathrm{g}$ for $10 \mathrm{~min}, 20$ $\mu \mathrm{L}$ of the supernatant was added into substrate solution and working solution of caspase- 3 or caspase- 9 for each assay. After being incubated at $37^{\circ} \mathrm{C}$ for an hour, the samples were read at a wavelength of $405 \mathrm{~nm}$ in microplate reader (Varioskan Flash, Thermo Scientific, USA). Another $10 \mu \mathrm{L}$ of the supernatant was diluted to the proper concentration range for protein determination using the Pierce BCA protein assay reagent kit (Pierce, USA) with bovine serum albumin as the standard. Each value obtained in this section was an average of triplicate measurements.

\section{Animal model}

Experiments were performed on Sprague-Dawley (SD) rats (male; body weight: $200 \pm 10 \mathrm{~g}$ ) obtained from the West China Experimental Animal Center of Sichuan University (China). All animal procedures were conducted in accordance with the animal use protocol approved by Sichuan University Animal Ethical Experimentation Committee (Chengdu, China).

Animals were maintained in a germ-free environment and allowed free access to food and water. The experimental rats were divided randomly into the following four groups: (i) Sal-I/R group, (ii) TP-I/R group, (iii) TPG-I/R group and (iv) Sham-operated group. The Sal-I/R group and Sham-operated group were administered the same volume of normal saline (NS, $0.9 \% \mathrm{NaCl}$ ) via caudal vein injection for 3 days before renal surgery. The TP-I/R group and TPG-I/R group were respectively treated with TP of $4.17 \mu \mathrm{mol} \cdot \mathrm{kg}^{-1} \cdot \mathrm{d}^{-1}$ or TPG of $4.17 \mu \mathrm{mol} \cdot \mathrm{kg}^{-1} \cdot \mathrm{d}^{-1}$ via caudal vein injection for $3 \mathrm{~d}$ before renal ischemia.

All rats were anesthetized with chloral hydrate $(275 \mathrm{mg} / \mathrm{kg})$ delivered intraperitoneally, and the kidneys were exposed through flank incisions. After laparotomy, the rats in Sal-I/R group, TP-I/R group and TPG-I/R group were subjected to $35 \mathrm{~min}$ of bilateral renal ischemia, which was induced by clamping both renal pedicles with nontraumatic microaneurysm clamps. The incisions were temporarily closed during ischemia or sham surgery. After the clamps were removed, the reperfusion of the kidneys was visually confirmed, and the incision was sutured. The sham-operated group rats were performed with the exposure of both kidneys without the 
induction of ischemia. The kidneys were harvested after $24 \mathrm{~h}$ of recovery from the surgery. The method of validating the success of the animal model was to assess the renal function markers blood urea nitrogen (BUN) and creatinine (CREA), as reported in a previous study ${ }^{[15]}$.

\section{Histological evaluation}

After fixation in $10 \%$ formalin for $48 \mathrm{~h}$, the kidney tissues were embedded in paraffin and sectioned using a paraffin microtome with stainless steel knives. The sections were mounted on glass slides, deparaffinized with xylene, dehydrated through a graded series of ethanol and stained with H\&E (hematoxylin and eosin) to allow histomorphological analysis. The stained sections were examined under an upright microscope system (Olympus DP27, Olympus Corporation, Japan).

\section{TUNEL assay}

TUNEL (terminal deoxynucleotidyl transferase biotin dUTP nick-end labeling) assays were performed using the In Situ Cell Death Detection Kit (Cat № 11684795 910, Roche Diagnostics $\mathrm{GmbH}$, Germany) to detect the level of in vivo apoptosis following the manufacturer's instructions. In brief, deparaffinized kidney sections were pretreated with $20 \mu \mathrm{g} / \mathrm{mL}$ Proteinase $\mathrm{K}$ for $20 \mathrm{~min}$ at $37^{\circ} \mathrm{C}$. After being washed, the sections were incubated with the TUNEL reaction solution for $60 \mathrm{~min}$ at $37^{\circ} \mathrm{C}$ and protected from light. The TUNEL reaction solution was a dUTP (deoxyuridine triphosphate) solution marked with FITC (fluorescein isothiocyanate) and the TdT (terminal enzyme deoxynucleotidyl transferase). Once the staining was complete, each sample was washed 3 times with PBS and counterstained with DAPI for $5 \mathrm{~min}$ and protected from light. After being washed three times with PBS, the sections were sealed by glycerol buffer and examined under a fluorescence microscope (Leica DM2000B, Leica Co Ltd, Germany).

\section{Oxidative stress analysis in vivo}

Renal I/R injury was associated with oxidative damage by altering antioxidant protection mechanisms. Specifically, the aim of this section was to evaluate the levels of nitric oxide synthase (NOS), superoxide dismutase (SOD), catalase (CAT) and malondialdehyde (MDA) in the kidneys from the four groups of rats.

\section{Nitric oxide synthase assay}

The level of NOS in I/R injured kidneys was assayed using a commercial kit (Catalog No KGT020-1, KeyGEN BioTECH, Nanjing, China) following the manufacturer's instructions. In brief, isolated rat kidneys were cleaned with ice-cold PBS, homogenized, diluted 1:10 in ice-cold PBS, and centrifuged at $1000 \times g$ for $10 \mathrm{~min}$ at $4^{\circ} \mathrm{C}$. Finally, an appropriate volume of the supernatant was spiked to assay the NOS. The levels were normalized to the protein concentration in each sample.

\section{Lipid peroxidation assay}

The level of MDA in I/R injured kidneys was assayed using a commercial kit (Catalog No KGT004, KeyGEN BioTECH,
Nanjing, China) following the manufacturer's instructions. In brief, isolated rat kidneys were cleaned with ice-cold PBS, homogenized, diluted 1:10 in ice-cold PBS, and centrifuged at $12000 \times g$ for $5 \mathrm{~min}$ at $4{ }^{\circ} \mathrm{C}$. Finally, an appropriate aliquot of the supernatant was spiked to assay the MDA. The levels were normalized to the protein concentration in each sample.

\section{Superoxide dismutase assay}

The level of SOD in I/R injured kidneys was assayed using a commercial kit (catalog No KGT001100, KeyGEN BioTECH) following the manufacturer's instructions. In brief, isolated rat kidneys were cleaned with ice-cold PBS, homogenized, diluted 1:10 in ice-cold PBS, and centrifuged at $12000 \times g$ for 5 $\min$ at $4^{\circ} \mathrm{C}$. Finally, an appropriate aliquot of supernatant was spiked to assay the SOD. These levels were normalized to the protein concentration in each sample.

\section{Catalase assay}

The level of CAT in I/R injured kidneys was assayed using a commercial kit (Catalog NO. KGT017, KeyGEN BioTECH) following the manufacturer's instructions. In brief, isolated rat kidneys were cleaned with ice-cold PBS, homogenized, diluted 1:10 in ice-cold PBS, and centrifuged at $600 \times \mathrm{g}$ for 10 min at $4^{\circ} \mathrm{C}$. Finally, an appropriate aliquot of supernatant was spiked to assay the CAT. The levels were normalized to the protein concentration in each sample.

\section{ELISA determination}

Commercial ELISA kits were used to analyze the kidney homogenates from Sal-I/R, TP-I/R, TPG-I/R and sham-operated rats for the levels of KIM-1(Catalog No RKM100, R\&D Systems, USA), ICAM-1 (Catalog No RIC100, R\&D Systems, USA), MCP-1 (Catalog No MJE00, R\&D Systems, USA), TNF- $a$ (Catalog No 88-7340-22, eBioscience, USA), IL-1 $\beta$ (Catalog № 88-6010-22, eBioscience, USA), IL-6 (Catalog № R6000B, R\&D Systems, USA) and TGF- $\beta$ (Catalog No MB100B, R\&D Systems, USA). All the operations were performed according to the manufacturer's instructions. The optical densities (OD) of the samples were measured at a wavelength of $450 \mathrm{~nm}$ (Varioskan Flash, Thermo Scientific, USA), and the concentrations of the samples were calculated according to the standard curve built in each plate.

\section{Immunohistochemistry studies}

Paraffin sections were deparaffinized and incubated in antigen retrieval buffer (citrate, $\mathrm{pH}$ ) for $40 \mathrm{~min}$ at $95^{\circ} \mathrm{C}$. The endogenous peroxidase activity was blocked by incubating sections with $3 \% \mathrm{H}_{2} \mathrm{O}_{2}$ for $15 \mathrm{~min}$ at room temperature in the dark. The sections were then washed with PBS and incubated overnight at $4{ }^{\circ} \mathrm{C}$ with the following primary antibodies: TNF- $\alpha$ (1:50; Abcam, ab6671), IL-1 $\beta$ (1:100; Abcam, ab9722), IL-6 (1:50; Abcam, ab9324), TGF- $\beta$ (1:100; Abcam, ab92486), KIM1(1:100; Abcam, ab47634), MCP-1 (1:200; Abcam, ab7202) and ICAM-1 (1:100; Abcam, ab171123). The sections were washed with PBS three times and then incubated for $45 \mathrm{~min}$ at $37^{\circ} \mathrm{C}$ with an appropriate volume of Agent A (HRP-conjugated 
ChemMate Envision reagent) using the anti-rabbit/rat general immunohistochemical test kit (Envision Detection Kit, Catalog No GK500705). A color reaction was developed by adding the appropriate volume of 3,3'-diaminobenzidine (Sigma). The sections were counterstained with hematoxylin and then cover slipped. Finally, all the stained slides were viewed on an upright metallurgical microscope (Olympus DP27, Olympus Corporation, Japan).

\section{Statistical analysis}

The quantitative data are expressed as the mean \pm SD (standard deviation) and analyzed by one-way ANOVA. Individual comparisons were performed using the Tukey method (post hoc test), with a $P$ value less than 0.05 defined as the threshold of significance.
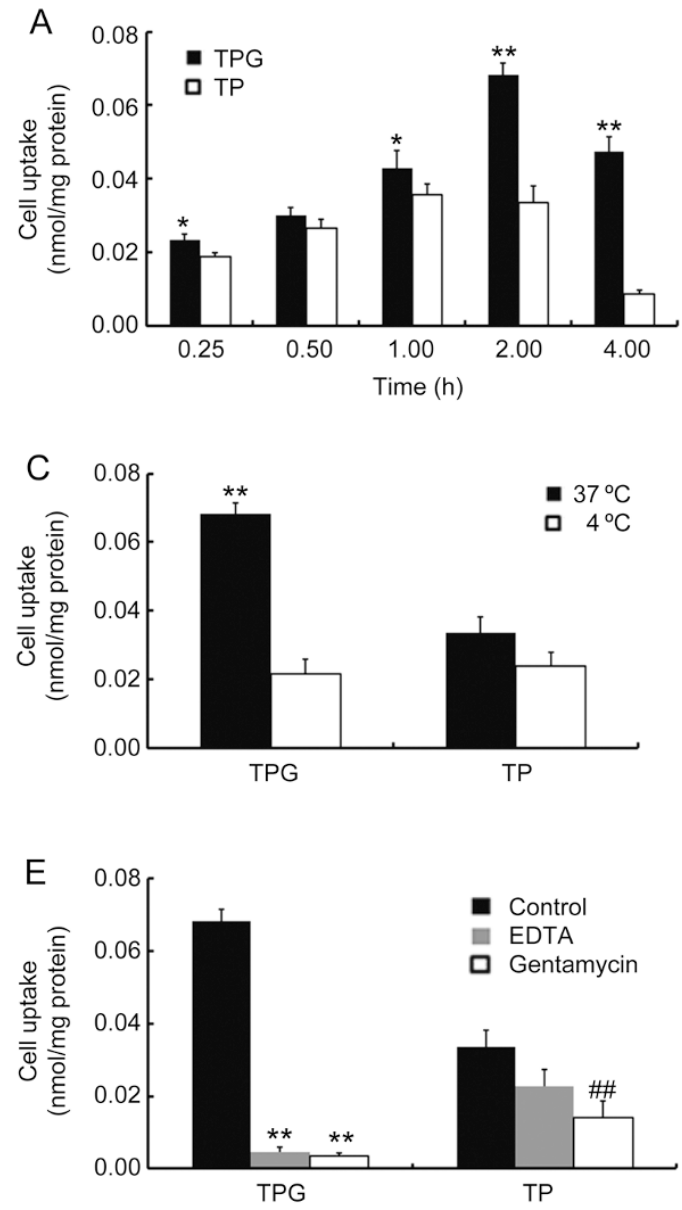

\section{Results}

TPG targeted renal tubular epithelial cells through interactions with megalin receptors

To directly assess the mechanism of renal targeting, quantifications of the cellular uptake of TP or TPG were carried out in HK-2 cells. We investigated the effect of time, concentration, temperature, different cell lines and the competitive inhibitors. The results showed that the cellular uptake of TPG was time-dependent (Figure 2A) and concentration-dependent (Figure 2B). Specifically, the cellular uptake of TPG showed significant augmentation at $2 \mathrm{~h}$ and $4 \mathrm{~h}$, with a 2.0- and 6.0fold increase compared with TP (Figure 2A). The cell uptake of TPG was 2.0 times higher than TP at the concentration of $0.2 \mathrm{nmol} / \mathrm{mL}$. When the concentration was $5 \mathrm{nmol} / \mathrm{mL}$, the uptake increased to 3.1-fold (Figure 2B).
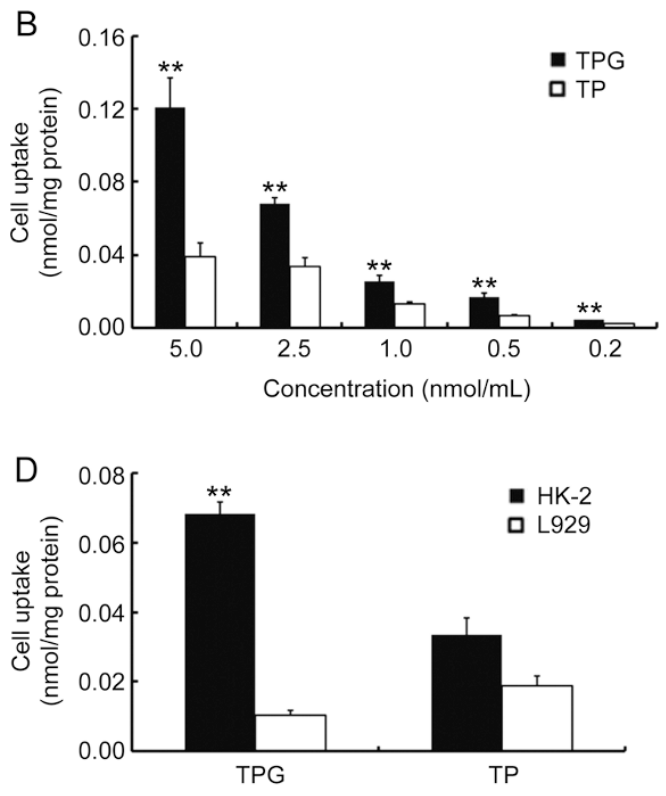

Figure 2. Time-, concentration-, and temperature-dependent TPG uptake by renal tubular epithelial HK-2 cells. (A) In vitro cellular uptake of TPG (2.5 $\mathrm{nmol} / \mathrm{mL})$ in HK-2 cells at different times $(0.25,0.5,1,2$, or $4 \mathrm{~h})$. TP as control group. Mean \pm SD. $n=5$. ${ }^{*} P<0.05,{ }^{* *} P<0.01$ vs the TP group. (B) In vitro cellular uptake of TPG in HK-2 cells at different doses $\left(0.2,0.5,1.0,2.5\right.$ or $5 \mathrm{nmol} / \mathrm{mL}$, respectively) at $37^{\circ} \mathrm{C}$ for $2 \mathrm{~h}$. TP as control group. Mean $\pm \mathrm{SD}$. $n=5$. ${ }^{*} P<0.05,{ }^{* *} P<0.01$ vs the TP group. (C) In vitro cellular uptake of TPG $(2.5 \mathrm{nmol} / \mathrm{mL})$ in HK-2 cells at different temperatures $\left(37\right.$ or $\left.4{ }^{\circ} \mathrm{C}\right)$ for $2 \mathrm{~h}$. TP as control group. Mean \pm SD. $n=5 .{ }^{* *} P<0.01$ vs the cellular uptake of TPG at $4^{\circ} \mathrm{C}$. (D) In vitro cellular uptake of TPG and TP $(2.5 \mathrm{nmol} / \mathrm{mL})$ in $\mathrm{HK}-2$ cells or L929 cells at $37^{\circ} \mathrm{C}$ for $2 \mathrm{~h}$. Mean \pm SD. $n=5 .{ }^{* *} P<0.01$ vs the cellular uptake of TPG in L929 cells. (E) Inhibition of cellular uptake of TP and TPG $\left(2.5 \mathrm{nmol} / \mathrm{mL}\right.$ ) by different inhibitors ( $1 \mathrm{mmol} / \mathrm{L}$ EDTA or $4 \mathrm{mg} / \mathrm{mL}$ gentamycin) at $37^{\circ} \mathrm{C}$ for $2 \mathrm{~h}$. Mean \pm SD. $n=5 .{ }^{* *} P<0.01$ vs the TPG group. ${ }^{\# \#} P<0.01$ vs the TP group. 
The findings demonstrated that TPG had an overt renaltargeting capability in the proximal tubule epithelium through its interaction with megalin receptors ${ }^{[19]}$. The cellular uptake of TPG revealed a significant difference between $4{ }^{\circ} \mathrm{C}$ and $37^{\circ} \mathrm{C}$ (Figure $2 \mathrm{C}$ ), which indicated the potential dependence of temperature. This finding suggested that TPG would interact with some transporters existing on HK-2 cells. The cellular uptake of TPG in HK-2 cells was far more than the uptake in L929 cells (Figure 2D), indicating the kidney targeting of TPG in vitro. Although the intracellular concentration of TP was also slightly decreased in L929 cells, there was no significant difference between the two cell lines. When the megalin receptor was inhibited by EDTA or gentamicin, the cellular uptake of TPG was substantially decreased in HK-2 cells (Figure $2 \mathrm{E}$ ). In the presence of the EDTA, the intracellular concentration of TPG declined to one-fifteenth of the control group. In the presence of the gentamicin, the cellular uptake of TPG dropped to 0.06 times of the uptake in the control group.

The transport of TPG by HK-2 cells was time-, concentra- tion- and temperature-dependent and involved the megalin receptor.

\section{TPG markedly ameliorated $\mathrm{G}_{2} / \mathrm{M}$ arrest in vitro}

To investigate how TPG had a much less cytotoxicity than TP in vitro, we complemented earlier studies ${ }^{[15]}$ with an evaluation of cell cycle distribution in HK-2 cells. As demonstrated by the flow cytometry analysis, the results presented in Figure 2 depicted a representative profile of cell cycle distribution in HK-2 cells.

Compared with $44.31 \%$ of $\mathrm{G}_{0} / \mathrm{G}_{1}$ phase in the control group (absence of TP or TPG), approximately $59.87 \%$ of the cells were arrested at the $G_{0} / G_{1}$ phase when treated with $40 \mathrm{nmol} / \mathrm{L}$ TP (Figure $3 \mathrm{~A}$ and $3 \mathrm{~B}$ ). When the cells were administered 80 or $160 \mathrm{nmol} / \mathrm{L} \mathrm{TP}$, the proportion of the $\mathrm{G}_{0} / \mathrm{G}_{1}$ phase was markedly decreased to $46.34 \%$ and $30.64 \%$, whereas the $G_{2} / M$ fraction increased from $7.87 \%$ to $22.28 \%$ or $39.14 \%$ (Figure $3 \mathrm{~A}$ and $3 \mathrm{~B})$. These findings showed that with the TP concentration increasing, there was an obvious and persistent arrest in $\mathrm{G}_{2} / \mathrm{M}$
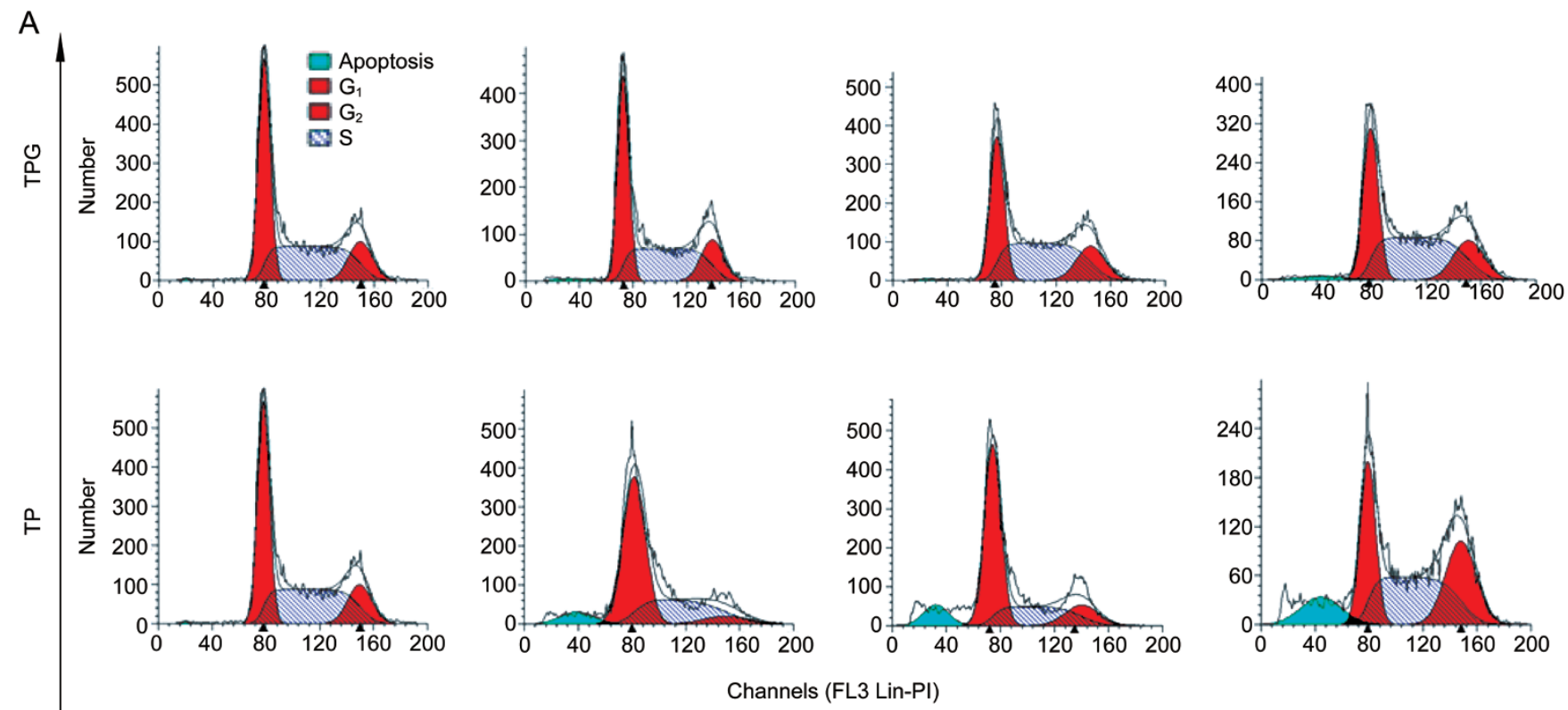

Channels (FL3 Lin-PI)

Control

B

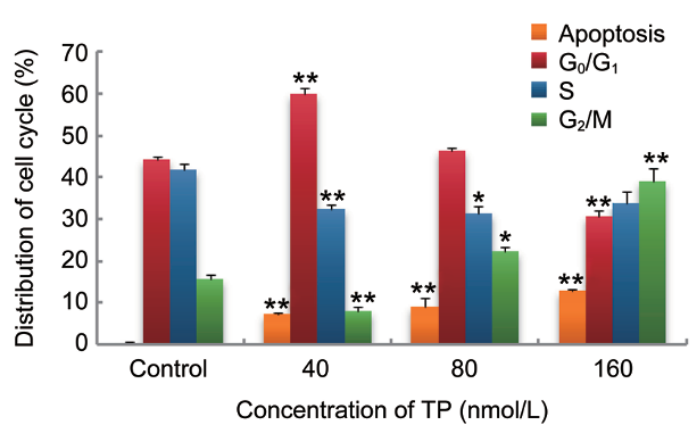

C

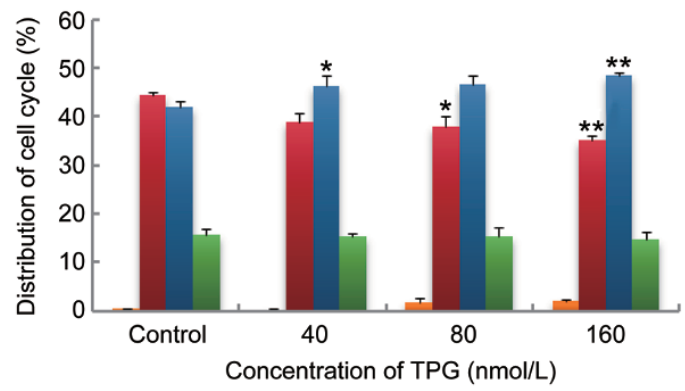

Figure 3. TPG markedly ameliorated $\mathrm{G}_{2} / \mathrm{M}$ arrest in vitro. (A) Representative profile of cell cycle distribution of HK-2 cells after being incubated with TP (B) or TPG (C) at various concentrations $(0,40,80$ or $160 \mathrm{nmol} / \mathrm{L})$ for $24 \mathrm{~h}$ at $37^{\circ} \mathrm{C}$. The distribution of cell cycle was stained by PI and detected by flow cytometry analysis. The figures were representative of three separate experiments. Mean \pm SD. $n=3$. ${ }^{*} P<0.05,{ }^{* *} P<0.01$ vs the control group $(0 \mathrm{nmol} / \mathrm{L})$. 
phase. However, cells exposed to TPG at each concentration did not show any significant difference of $\mathrm{G}_{2} / \mathrm{M}$ phases in cell cycle distribution compared with the control group (Figure 3A and $3 \mathrm{C}$ ). Only a slight accumulation of $S$ phase was detected in the presence of $160 \mathrm{nmol} / \mathrm{L}$ TPG. Moreover, we observed distinct apoptosis in TP-treated cells, which was concentration-dependent (Figure 3A), but this feature barely occurred in the TPG treated cells. Therefore, we concluded that TPG ameliorated $\mathrm{G}_{2} / \mathrm{M}$ arrest and apoptosis of HK-2 cells compared with TP.

\section{TPG only induced slight apoptosis in vitro}

To determine the apoptosis rate induced by TP or TPG in vitro, we treated HK-2 cells with Annexin V-FITC/PI staining and then processed the cells for flow cytometry, followed by caspase- 3 and caspase- 9 activity assay. A double labeling assay consisting of annexin $\mathrm{V}$ combined with PI showed an explicit distinction of late apoptotic (annexin $\mathrm{V}^{+} / \mathrm{PI}^{+}$) and early apoptotic cells (annexin $\mathrm{V}^{+} / \mathrm{PI}^{-}$). HK-2 cells treated with TP at a dose of 40,80 or $160 \mathrm{nmol} / \mathrm{L}$ for $24 \mathrm{~h}$ exhibited a substan- tial increase in annexin $\mathrm{V}^{+} / \mathrm{PI}^{-}$. The early apoptosis rate was respectively $18.03 \%, 24.50 \%$ and $44.40 \%$, which was in a dosedependent manner. All of these rates were statistically lower than in the TPG group $(10.70 \%, 13.97 \%$ or $15.73 \%$ ) (Figure $4 \mathrm{~A}$ and $4 \mathrm{~B})$.

In addition, to verify if the cell apoptosis induced by TP or TPG was dependent on caspase activation, caspase- 3 and caspase-9 activity was characterized (Figure 4C and 4D). After treatment with TPG for $24 \mathrm{~h}$, there was no significant difference in caspase- 3 and caspase- 9 activity at each concentration (40, 80 or $160 \mathrm{nmol} / \mathrm{L})$ compared with the control group. However, we detected a marked up-regulation of caspase-3 and caspase- 9 expression in TP-treated groups. For example, caspase- 3 activity was 6.74 times and caspase- 9 activity was 2.53-fold of the control group at the concentration of 160 nmol/L.

Taken together, these results suggested that TP would induce apoptosis in HK-2 cells, and the mechanism was associated with caspase- 3 and caspase-9. However, all of these changes were highly reduced in the TPG-treated groups.
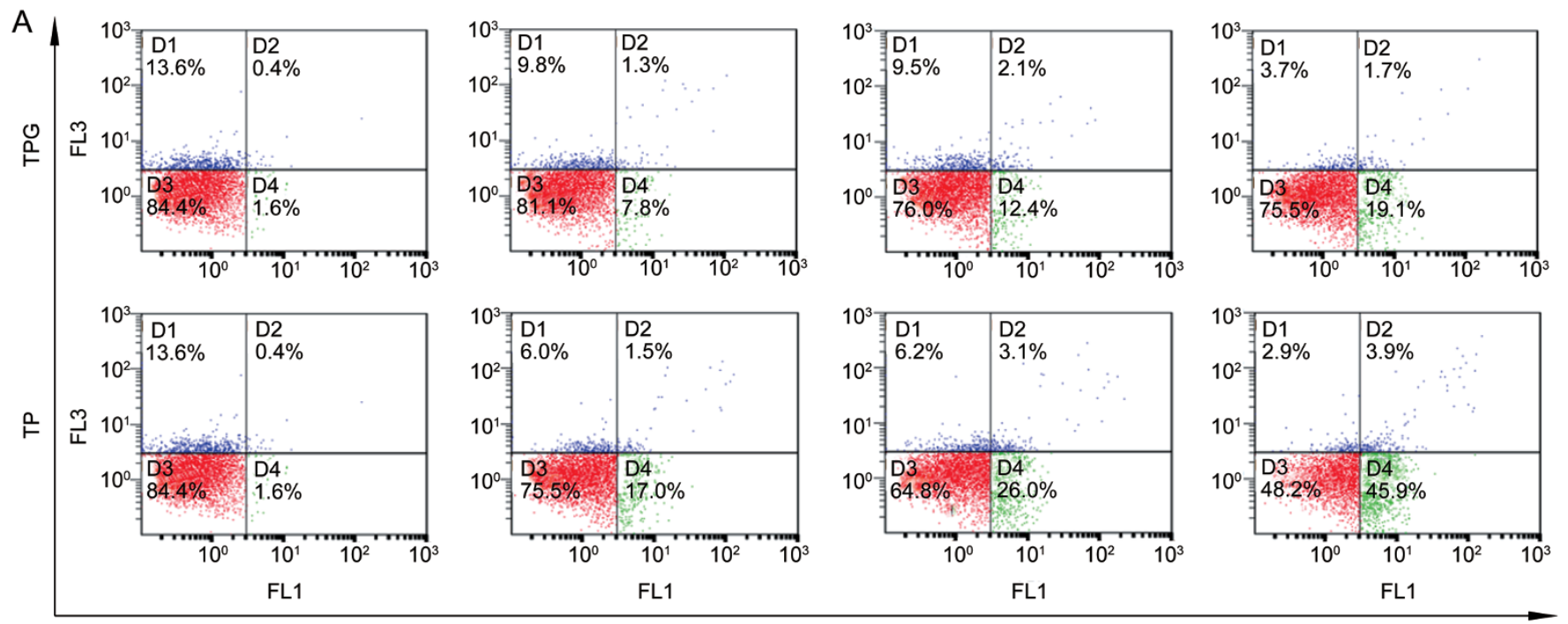

Control

$40 \mathrm{nmol} / \mathrm{L}$

$80 \mathrm{nmol} / \mathrm{L}$

$160 \mathrm{nmol} / \mathrm{L}$
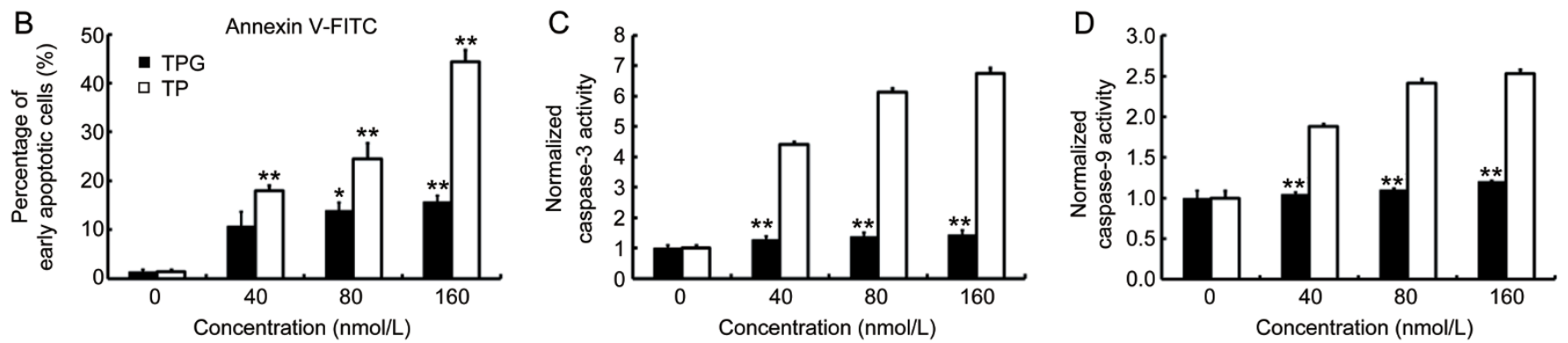

Figure 4. TPG only induced a slight apoptosis in vitro. (A) Representative images of flow cytometry analysis of HK-2 cells after being exposed to TP and TPG at different concentrations $(0,40,80$, or $160 \mathrm{nmol} / \mathrm{L})$ for $24 \mathrm{~h}$ at $37^{\circ} \mathrm{C}$. (B) The percentage of early apoptotic cells in HK-2 cells after administration of TP or TPG at each concentration point. Mean \pm SD. $n=3$. ${ }^{*} P<0.05,{ }^{* *} P<0.01$ vs control group ( 0 nmol/L). (C) Caspase-3 activity and (D) caspase- 9 activity of HK-2 cells treated with TP or TPG at $0,40,80$, or $160 \mathrm{nmol} / \mathrm{L}$ for $24 \mathrm{~h}$ at $37^{\circ} \mathrm{C}$. Mean \pm SD. $n=3$. ${ }^{* *} P<0.01$ vs TP group at the same concentration. 
Therefore, we drew the conclusion that TPG induced a much lower apoptosis rate than TP in HK-2 cells.

\section{TPG alleviated I/R-induced apoptosis and necrosis in rats}

In recent years, several laboratories reported evidence of apoptotic cell death during I/R injury ${ }^{[20]}$. To reveal the enhanced ability of TPG to alleviate injury induced by I/R, we analyzed the overall morphology and the level of apoptosis of the kidneys recovering $24 \mathrm{~h}$ after surgery.

The tissues in the sham-operated group showed imperceptible pathological changes (Figure 5). These tissues presented remarkable altered tubular morphology in the Sal-I/R group, including massive tubular lumen dilatation, tubular degeneration, cell swelling and necrosis. Compared with the TP-I/R group, the TPG-I/R group showed better preserved morphology and lower degeneration of tubular cells in the kidneys.
To be specific, the apoptotic index of TUNEL staining in the sham-operated group was approximately $9.0 \%$, while it significantly increased to approximately $45 \%$ in the SAL-I/R group. The increased apoptosis occurred mostly in the proximal tubule. A lower apoptotic index was obtained in the TPG-I/R group $(18.50 \%)$ than that in the TP-I/R group $(32.40 \%)$, indicating that TPG had improved attenuation of the kidney in $\mathrm{I} / \mathrm{R}$ injury.

\section{TPG mitigated I/R-induced oxidative stress in rats}

The immunohistochemical and the biochemical evidence demonstrated the production of reactive oxygen species (ROS) during I/R injury ${ }^{[21]}$. The potential ROS sources described to date have gained status as the most likely contributors to oxidative stress induced by reperfusion ${ }^{[22]}$. Compared with the sham-operated group, I/R injury resulted in a significant
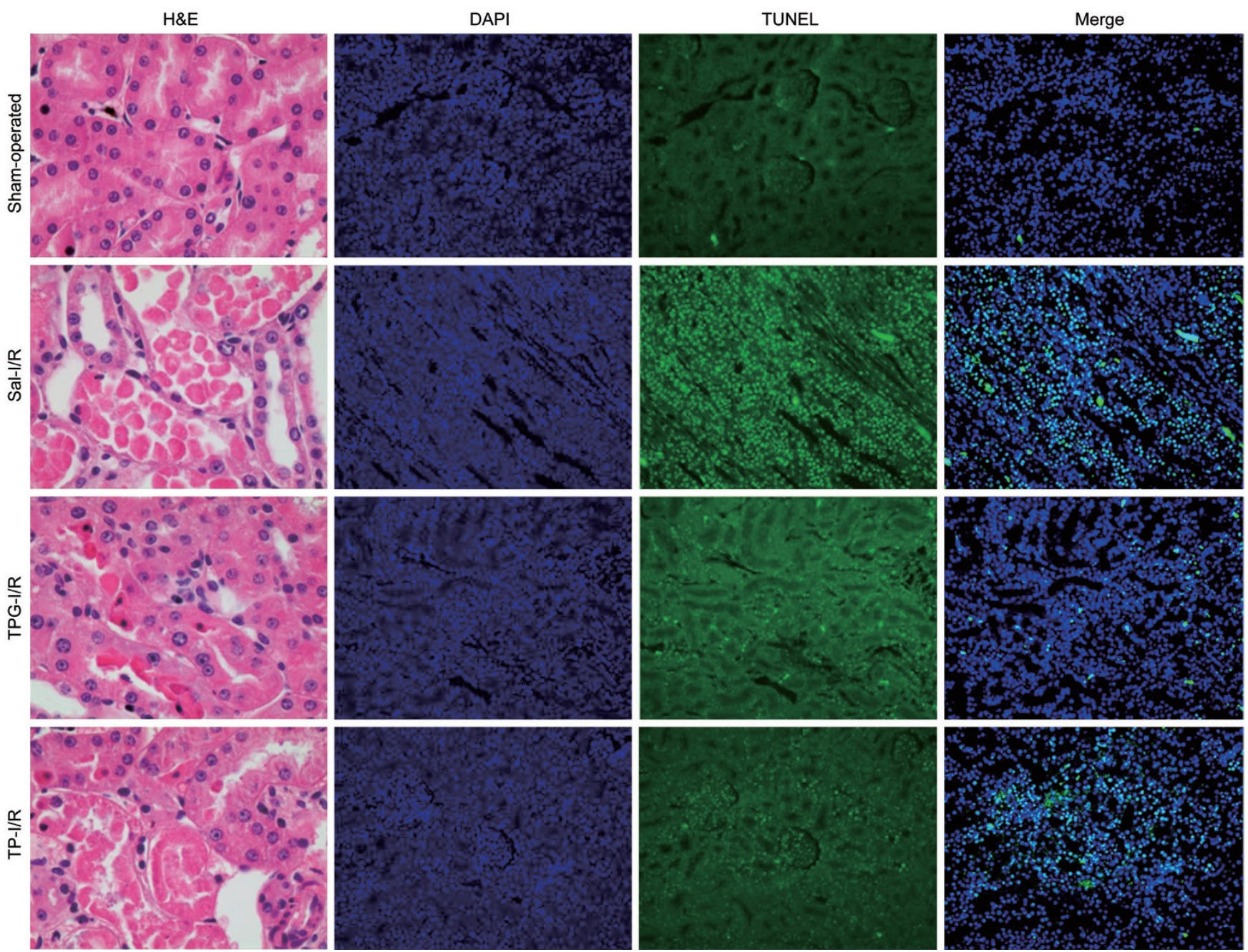

Figure 5. TPG alleviated I/R-induced apoptosis and necrosis in rats. H\&E staining and TUNEL assay were conducted in kidneys from rats which were subjected to ischemia and reperfusion (I/R) injury following pretreatment with saline (Sal-I/R), triptolide (TP-I/R) or triptolide-glucosamine conjugate (TPG-l/R) at $24 \mathrm{~h}$ after surgery, as well as sham-operated rats. I/R injury induced severe altered tubular morphology and apoptosis in kidney tissue. TPG-I/R group present a much better preserved morphology and a lower percentage of kidney apoptosis versus TP-I/R group. Photomicrographs of H\&E staining were taken with a microscope camera at 400x magnification, and photomicrographs of TUNEL assay were taken with a microscope camera at $200 \times$ magnification. 
reduction in SOD (Figure 6A) and CAT (Figure 6B) activity, which could neutralize the free oxygen radicals ${ }^{[23]}$, as well as a significant increase in the levels of MDA (Figure 6C) and NOS (Figure 6D). All of these features were attenuated after the administration of TP or TPG and were attenuated to a greater extent with TPG than TP.

The levels of SOD and CAT in the TPG-I/R group were $72.89 \%$ and $72.5 \%$ of the sham-operated group and were $49.11 \%$ and $50.75 \%$ of the sham-operated group in the TP-I/R group. Compared with the TP-I/R group, the TPG-I/R group showed that the level of MDA was markedly decreased (Figure 6C); MDA acted as a marker of radical induced lipid peroxidation $^{[24]}$. The level of NOS, which served as an index of the NO burden, was 1.98-fold of the sham-operated group in the TP-I/R group. However, this level was only 1.77-fold of the sham-operated group in the TPG-I/R group. These results demonstrated that the oxidative stress damage was mitigated to a greater extent in the TPG-I/R group than in the TP-I/R group, which contributed to the lower amounts of lipid peroxidation and the higher antioxidant activity.

\section{TPG suppressed I/R-induced inflammation in rats}

There is little doubt that inflammation plays an important role in the development and progression of most cases of acute renal failure ${ }^{[11]}$. The levels of proinflammatory cytokines, including interleukin-1 (IL-1), interleukin-6 (IL-6), tumor necrosis factor-alpha (TNF-a) and transforming growth factorbeta1 (TGF- $\beta 1$ ), were determined to assess the anti-inflammatory activity of TPG in the I/R injured kidneys.

Compared with the sham-operated group, the Sal-I/R group
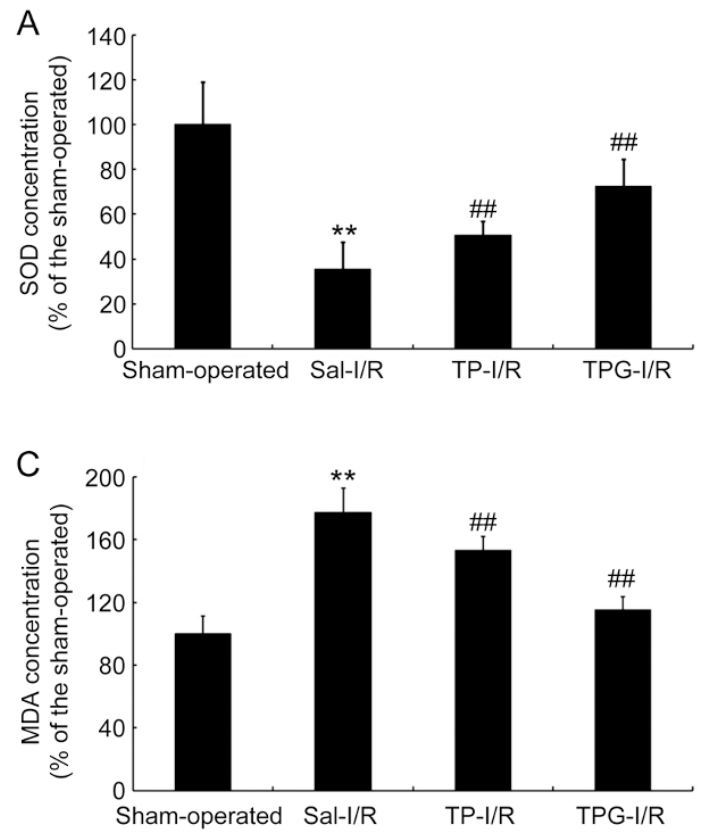

showed overt increased expression of TNF- $\alpha$, IL-1 $\beta$ and IL-6 (Figure 7A, 7B and 7D). This finding is consistent with the fact that the initial inflammation is caused by cytokine-mediated endocytosis or phagocytosis. During the process, the neutrophils are the first cells recruited, and these cells phagocytose apoptotic bodies and release inflammatory and profibrogenic cytokines $^{[9]}$. Compared with the TP-I/R group, the TPG-I/R group showed a lower level of TNF-a, which exceeded only $16.2 \%$ of the sham-operated group. Moreover, the levels of IL-1 $\beta$ and IL-6 were lower in the TPG-pretreated rats than in the TP-pretreated group. Consistent with these results from ELISA determinations, immunohistochemistry of the kidney sections revealed that $I / R$ injury would increase the expression of TNF- $\alpha$, IL-1 $\beta$ and IL- 6 in tubules, and pretreatment with TPG attenuated these features to a greater extent compared with pretreatment with TP (Figure 7A, 7B and 7D).

Because TGF- $\beta$ is also involved in the recruitment of macrophages, we examined the TGF- $\beta$ expression by ELISA determination and immunohistochemistry (Figure 7C). Similar results were obtained; the TGF- $\beta$ level in the TPG-I/R group was much lower than in the TP-I/R group. Although the pathogenesis of inflammation is complex and multifactorial, our study partially revealed the mechanism of the anti-inflammatory activity of TPG.

TPG inhibited immunocyte adhesion, infiltration and proliferation Kidney injury molecule-1 (KIM-1), an immunoglobulin super family cell-surface protein up-regulated on the surface of injured kidney epithelial cells, has been qualified as a highly sensitive and specific biomarker to monitor kidney injury ${ }^{[25,26]}$.
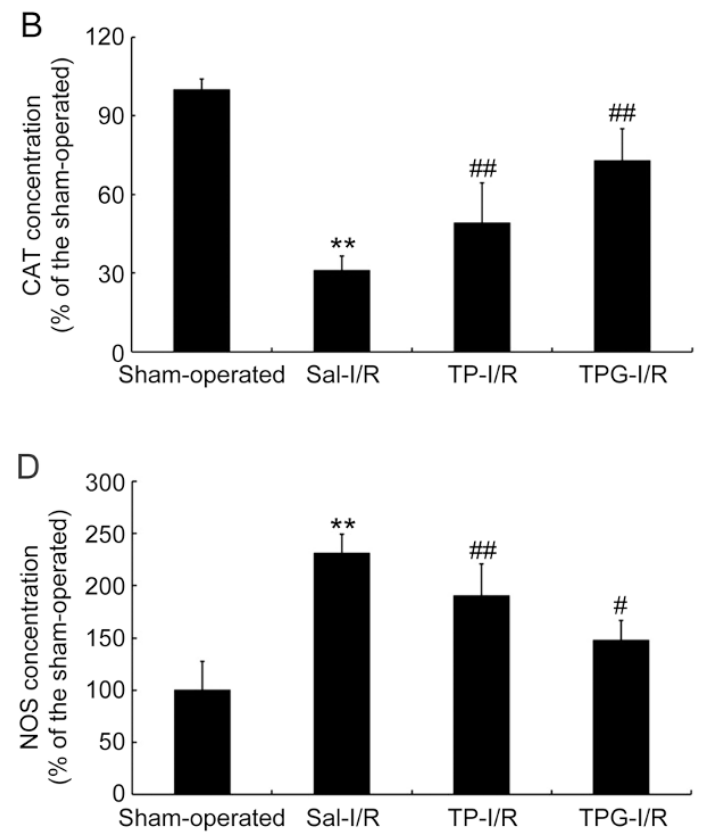

Figure 6. TPG mitigated I/R-induced oxidative stress in rats which results in lower accumulation of lipid peroxidation and higher antioxidant activity. Kidneys of rats were subjected to ischemia and reperfusion (I/R) injury following pretreatment with saline (Sal-I/R), triptolide (TP-I/R), triptolideglucosamine conjugate (TPG-1/R), as well as sham-operated rats. At $24 \mathrm{~h}$ after l/R, indicators of oxidative damage in kidneys: SOD (A), CAT (B), MDA (C), and NOS (D) were determined using commercial kits. Mean \pm SD. $n=5 .{ }^{* *} P<0.01$ vs the sham-operated group. ${ }^{\#} P<0.05,{ }^{\# \#} P<0.01$ vs Sal-I/R group. 

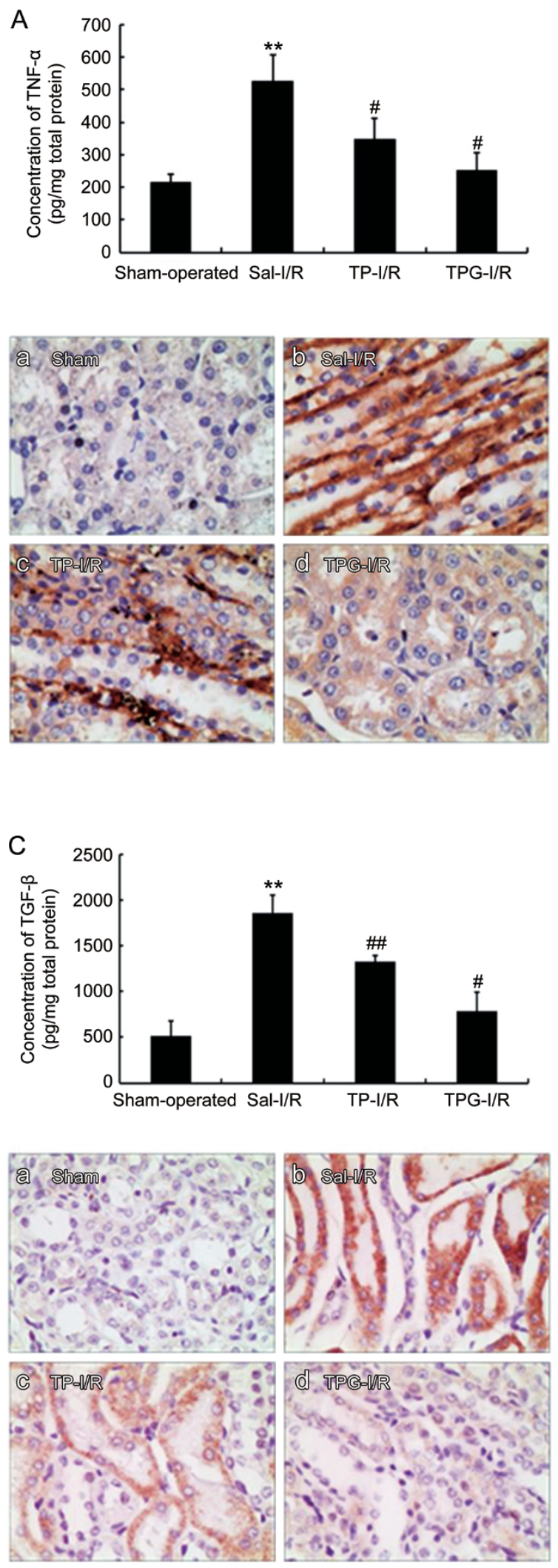
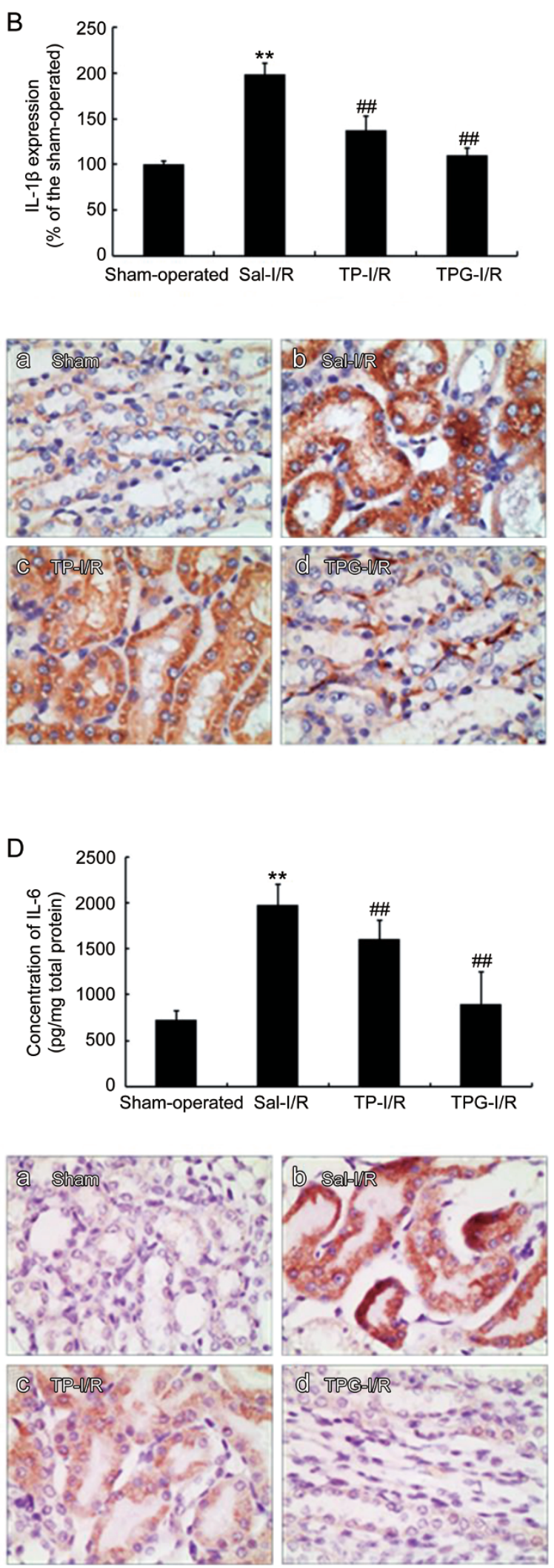

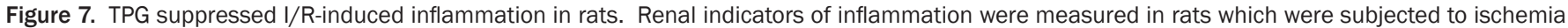

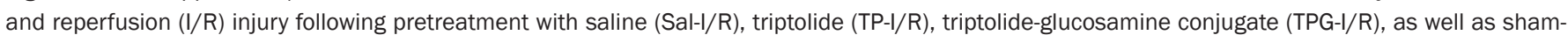

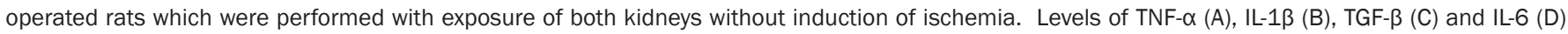

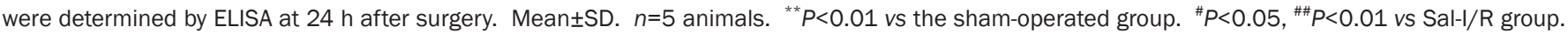
Photomicrographs were taken with a microscope camera at $400 \times$ magnification. 
Based on the ELISA determination, the level of KIM-1 was highly increased in the Sal-I/R group compared with the level of the sham-operated group at $24 \mathrm{~h}$ after the surgery (Figure 8A). The KIM-1 expression in the TPG-I/R group was 35.01\% relative to the level in the Sal-I/R group and $58.39 \%$ relative to the level in the TP-I/R group, which was in accordance with the immunohistochemistry staining results. Both TP and TPG could partially attenuate the injury, and TPG exerted even stronger attenuation.

The infiltration of monocytes/macrophages is facilitated by chemotactic factors and adhesion molecules. Monocyte chemoattractant protein-1 (MCP-1) is a potent chemokine stimulating monocyte migration into the intima of arterial walls and organs ${ }^{[27]}$. Immunohistochemistry against MCP-1 showed that $\mathrm{I} / \mathrm{R}$ injury increased its accumulation in the tubular tissue, and TPG effectively blocked this increase (Figure 8B). ELISA further revealed that the level of MCP-1 in the TPG-I/R group was $30.85 \%$ of the level in the Sal-I/R group and $68.74 \%$ of the level in the TP-I/R group (Figure $8 \mathrm{~B}$ ), which is indicative of the greater infiltration inhibition of TPG.

Intercellular adhesion molecule 1 (ICAM-1) plays an essential role in immunocyte adhesion in I/R injury and impinges on leukocytes to invade injured tissue, generates proteolytic enzymes and releases cytokines ${ }^{[28]}$. ICAM-1 might also lead to oxygen-free radical generation and tissue infiltration in injured kidneys $^{[28]}$. Therefore, we used ELISA to analyze the level of ICAM-1 in the injured kidneys after $24 \mathrm{~h}$ recovery from the
I/R surgery. The ICAM-1 level in the TPG-I/R group was $60.23 \%$ of the level in the Sal-I/R group and $71.21 \%$ of the level in the TP-I/R group; these findings were consistent with the immunohistochemistry staining of kidney sections (Figure $8 \mathrm{C})$. Therefore, pretreatment with TPG could more robustly reduce the expression of ICAM-1 than pretreatment with TP.

Pretreatment with TPG in renal I/R injury could downregulate immunocyte adhesion, chemoattractant protein and infiltration, which are caused by inflammatory cells involving neutrophils, macrophages and lymphocytes.

\section{Discussion}

With respect to the renal target, TPG accumulated specifically in proximal tubule renal cells by interacting with megalin receptors, which are widely expressed in the renal proximal tubule and function in proximal tubular reabsorption. Earlier studies demonstrated that the uptake of aminoglycosides was directly correlated with renal megalin activity ${ }^{[29]}$. Low molecular weight chitosan could also be specifically taken up by renal tubular cells, where megalin receptors likely mediate the binding and uptake ${ }^{[30]}$. 2-Glucosamine, which has a simple molecular structure and a high degree of safety, would be an ideal renal targeting carrier $^{[31]}$. Based on this hypothesis, we designed and synthesized TPG (a conjugate of 2-glucosamine and triptolide) in our previous studies ${ }^{[15]}$, and TPG showed an excellent kidney targeting property in vivo. Now, we conducted further investigations to assess the mechanism of the
A
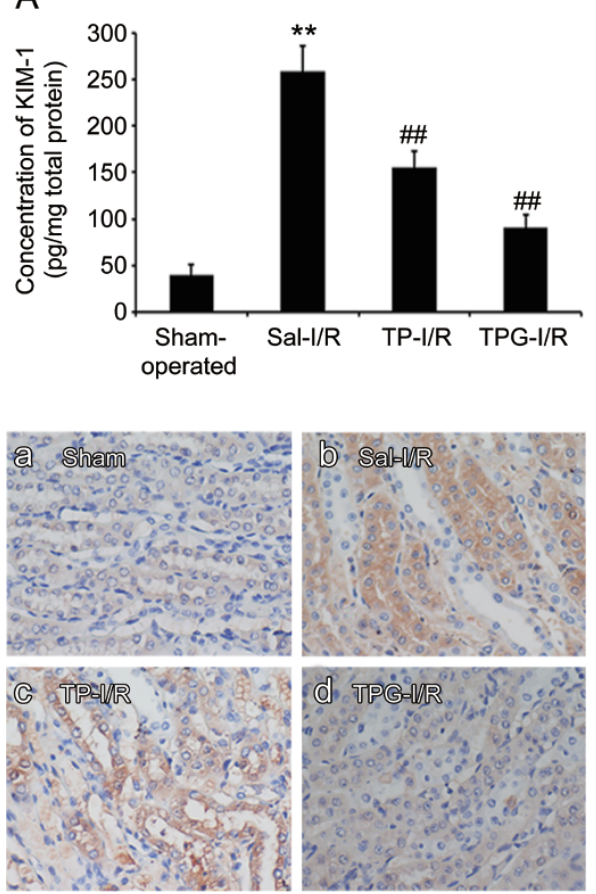

B
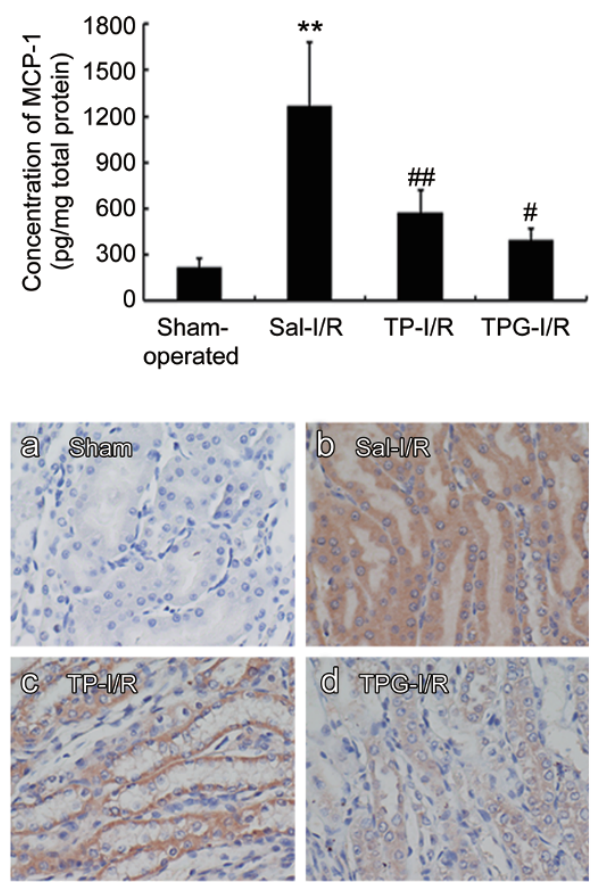
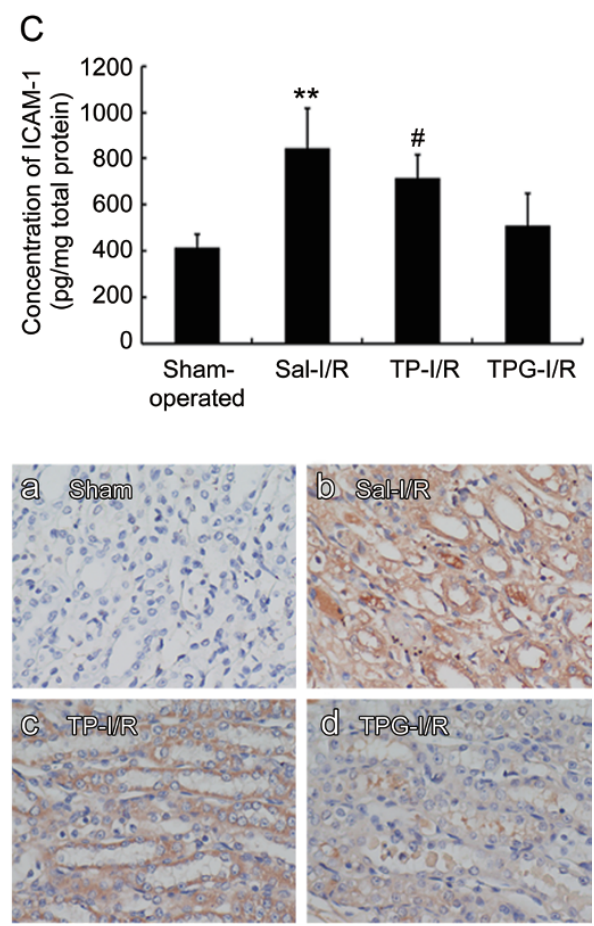

Figure 8. TPG inhibited immunocyte adhesion, infiltration, and proliferation. Renal expression of KIM-1 (A), MCP-1 (B) and ICAM-1 (C) were measured using ELISA commercial kits in rats, which were subjected to ischemia and reperfusion (I/R) injury following pretreatment with saline (Sal-I/R), triptolide (TP-I/R), triptolide-glucosamine conjugate (TPG-I/R), as well as sham-operated rats which were performed with exposure of both kidneys without induction of ischemia at $24 \mathrm{~h}$ after surgery. The upper panel was ELISA determination. Mean \pm SD. $n=5$ animals per condition. ${ }^{* *} P<0.01$ vs the shamoperated group. ${ }^{\# P}<0.05,{ }^{\# \#} P<0.01$ vs Sal-I/R group. Photomicrographs were taken with a microscope camera at $400 \times$ magnification. 
renal target of TPG, laying some foundations for novel renal target therapeutic strategies based on 2-glucosamine.

Subsequently, we characterized the cell cycle profile of tubular epithelial cells that were exposed to various concentrations of TP or TPG in vitro. We attempted to verify if there is a relationship between cytotoxicity and cell cycle arrest. Increasing evidence proves that modulating cell cycle arrest could affect the severity of acute ischemic kidney injury ${ }^{[32,33]}$. Some studies demonstrated that there was a causal association between epithelial cell cycle $\mathrm{G}_{2} / \mathrm{M}$ arrest and fibrotic outcomes in ischemic, toxic and obstructive models of $\mathrm{AKI}^{[34]}$. The expression of cell cycle regulatory proteins (such as p53, p21 and p16) modulated $\mathrm{G}_{2} / \mathrm{M}$ arrest in renal proximal tubular cells and highly corresponded with the inhibition of cell proliferation. TP possessed a concentration-dependent $\mathrm{G}_{2} / \mathrm{M}$ arrest whereas TPG did not have this ability. The findings agreed with a previous study showing that conjugating 2-glucosamine to TP significantly reduced its cytotoxicity in vitro ${ }^{[15]}$. In addition to the initial immunosuppressive and anti-inflammatory activity against renal injury, we conjectured that TPG might affect kidney fibrosis progression to some extent in later stages of renal failure. Further research is required to identify the cell cycle profile of tubular epithelial cells in vivo.

Apoptosis is an autonomously programmed cell death mechanism that could be initiated via two main pathwaysthe death receptor-mediated extrinsic pathway and the mitochondria-mediated intrinsic pathway. The complex processes of the two pathways are orchestrated by caspases, a family of cysteine proteases with unique substrate specificities ${ }^{[35]}$. For HK-2 cells, our data demonstrated that TP induced notable apoptosis in a dose-dependent manner, and caspase- 3 and caspase-9 were activated. Caspase-9, which is known as an initiator caspase in the intrinsic pathway, could lead to the activation of caspase-3. Caspase-3, which is known as an apoptosis executioner, subsequently cleaves a range of substrates, ie, PARP (poly adenosine diphosphate ribose polymerase), leading to chromosomal DNA breaks and the occurrence of apoptosis.

In the I/R rat model, compared with the TP-I/R group or the Sal-I/R group, there was increased amelioration of apoptosis of renal epithelial cells tubules in the TPG-I/R group. This result might occur by one or several of the following mechanisms: (i) due to the renal target property, more renal accumulation of TPG at the same dose of TP; (ii) TPG, with a main structure similar to $\mathrm{TP}$, might still have anti-inflammatory and immunosuppressive activity, including the down-regulation of inflammatory mediators (ie, MMP and NO) and cytokines (such as IL-1, IL-6, TNF- $\alpha$ and chemotactic factor) ${ }^{[36]}$; and (iii) conjugation of 2-glucosamine highly reduced the renal toxicity.

I/R injury triggers a series of ROS, proinflammatory cytokines and chemotactic cytokines ${ }^{[37,38]}$. During the process, the cytokines released in the initial period could activate leukocytes, such as macrophages, dendritic cells, $\mathrm{T}$ cells and mast cells. These cells would promote immunocytes to be recruited to inflammation sites, further aggravating cell injury ${ }^{[39,40]}$.
Regarding the superior protection of TPG in the I/R-induced injury, we extended our study to assess the degree of ROS, immunocyte infiltration, proinflammatory cytokines and chemotactic cytokines in vivo. Kidneys from the TPG-I/R group had a lower expression of KIM-1, which is a marker used to monitor kidney injury. This finding confirmed that TPG was pharmacologically active in the kidney. The study also indicated that a wide range of inhibition of proinflammatory cytokines (TNF- $\alpha$, IL-1 $\beta$ and IL-6) by TPG was the key to protecting kidneys from I/R injury, because these cytokines were activated as soon as the ischemic injury occurred. The interaction of endothelial cells and leukocytes promoted the release of ROS; therefore, more neutrophils were accumulated to enhance the inflammation response ${ }^{[41]}$. Therefore, lower levels of proinflammatory cytokines would contribute to inhibiting the neutrophil infiltration and the oxidant release, which supports the fact that TPG could reduce the generation of free oxygen radicals in the TPG-I/R group.

Oxidative stress plays a key role in I/R injury ${ }^{[42,43]}$. This stress modifies phospholipids and proteins, contributing to lipid peroxidation and oxidation of various cellular proteins ${ }^{[4]}$. In kidneys from the TPG-I/R group, TPG highly up-regulated the deactivators of ROS (SOD and CAT) and down-regulated the levels of MDA, ameliorating altered membrane permeability and configuration. TPG also reduced NO production by inhibiting NOS expression in the tubule cells. TPG presumably prevented peroxynitrite formation and attenuated oxidative stress, thereby alleviating I/R injury to a great extent.

Enhanced MCP-1 expression in rat kidneys during I/ R injury is mediated by oxidative stress and NF- $\mathrm{KB}^{[27]}$. TPG could partially reduce the level of MCP-1, which is one of the multiple pathways to inhibit the infiltration of monocytes/ macrophages into the damaged tissue, preventing I/R injury from getting worse.

ICAM-1, acting via the potentiation of neutrophil-endothelial interactions and obstruction of the venous vasa recta, is another key mediator of ischemic acute renal failure ${ }^{[45]}$. I/R injury would up-regulate the expression of ICAM-1, whereas TPG substantially blocked the increase to a greater extent than TP did. TPG provided superior protection against the adhesion of leukocytes to the endothelium. Regarding the inhibition of ICAM- 1 by TPG, there might be a combination of the reduction of free oxygen radicals, the down-regulation of cytokines and the synthetic inhibition of MCP-1 expression.

The current study focused on the results (Figure 9) showing that (i) TPG could target proximal tubules through the interaction with megalin receptors in HK-2 cells, and (ii) mitigated the degree of the $\mathrm{G}_{2} / \mathrm{M}$ arrest and the level of apoptosis, compared with TP. Furthermore, (iii) TPG could significantly attenuate renal I/R injury by inhibiting the proinflammatory cytokines and the leukocyte chemotactic molecules and by (iv) reducing the production of reactive oxygen species and adhesion molecules. The current study suggests that TPG merits further study in clinical trials as a potential next-generation treatment for immunological renal diseases. 

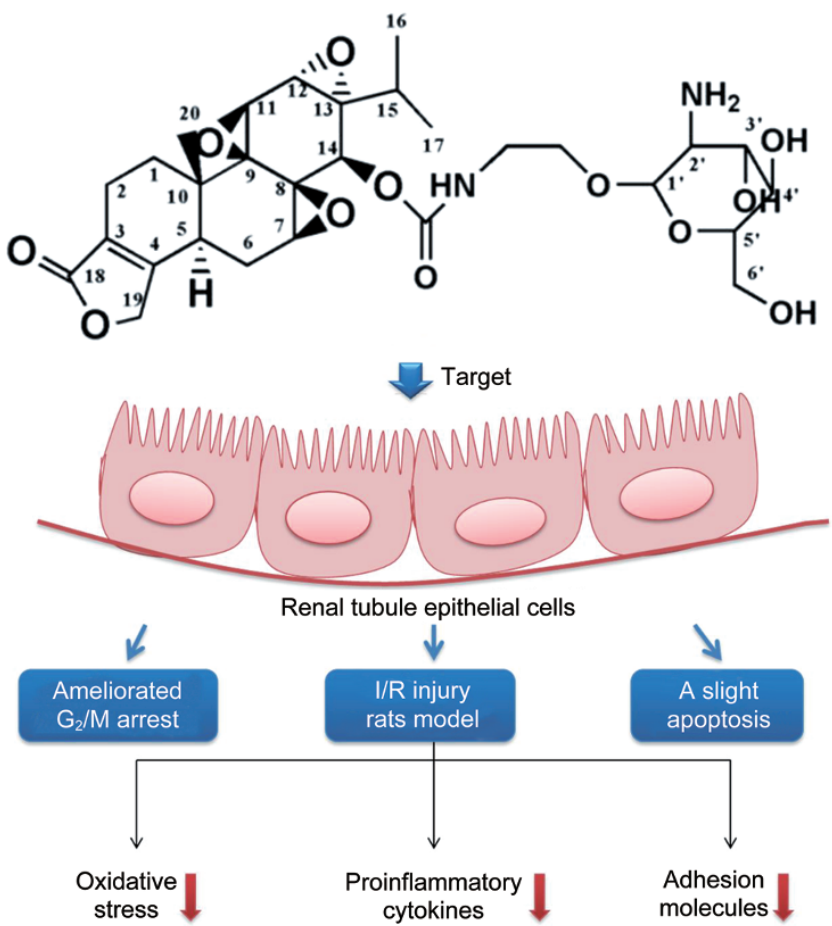

Figure 9. Schematic representation of connections among detected parameters.

\section{Acknowledgements}

This work was funded by the National Natural Science Foundation of China (№ 81473169).

\section{Author contribution}

Zhi-rong ZHANG and Yu FU designed the research; Zhi-rong ZHANG, Tao GONG, and Xun SUN contributed reagents or analytic tools; Yu FU and Qing LIN performed the research, analyzed the data and wrote the paper.

\section{References}

1 Holger KE, Tobias E. Ischemia and reperfusion-from mechanism to translation. Nat Med 2011; 17: 1391-401.

2 Forbes JM, Hewitson TD, Becker GJ, Jones CL. Ischemic acute renal failure: long-term histology of cell and matrix changes in the rat. Kidney Int 2000; 57: 2375-85.

3 Macedo E, Bouchard J, Mehta R. Renal recovery following acute kidney injury. Curr Opin Crit Care 2008; 14: 660-5.

4 Liu HF, Liang D, Wang LM, Zhou N, Yao CW, Hong T, et al. Effects of specific interle kin-1ß-converting enzyme inhibitor on ischemic acute renal failure in murine models. Acta Pharmacol Sin 2005; 26: 134551

5 Goncalves GM, Castoldi A, Braga TT, Camara NOS. New roles for innate immune response in acute and chronic kidney injuries. Scand J Immunol 2011; 73: 428-35.

6 Wu PF, Zhang Z, Wang F, Chen JG. Natural compounds from traditional medicinal herbs in the treatment of cerebral ischemia/reperfusion injury. Acta Pharmacol Sin 2010; 31: 1523-31

7 Suroj S, Weijia Z, Raju K, Kaskel FJ, Moore LC. Differential gene expression following early renal ischemia/reperfusion. Kidney Int 2003; 63: 1714-24.

8 Devarajan P. Update on mechanisms of ischemic acute kidney injury. J Am Soc Nephrol 2006; 17: 1503-20.

9 Lee SB, Kalluri R. Mechanistic connection between inflammation and fibrosis. Kidney Int 2010; 78: S22-6.

10 Ryota T, Yu I, Hitoshi M, Azusa K, Saori N, Hiroshi W, et al. Albumin fusion prolongs the antioxidant and anti-inflammatory activities of thioredoxin in mice with acetaminophen-induced hepatitis. Mol Pharm 2014; 11: 1228-38.

11 Xiao MM, David J, Nikolic P, Hui YL. Inflammatory processes in renal fibrosis. Nat Rev Nephrol 2014; 10: 493-503.

12 Daha M R, Kooten CV. Is the proximal tubular cell a proinflammatory cell? Nephrol Dial Transplantm 2000; 15: 41-3.

13 Dolman MEM, Harmsen S, Storm G, Hennink WE, Kok RJ. Drug targeting to the kidney: advances in the active targeting of therapeutics to proximal tubular cells. Adv Drug Delivery Rev 2010; 62: 1344-57.

14 Zhou P, Sun X, Zhang ZR. Kidney-targeted drug delivery systems. Acta Pharm Sin B 2014; 4: 37-42.

15 Zhou P, Sun X, Gong T, Zhang ZR, Zhang L. Conjugating glucosamine to triptolide to enhance its protective effect against renal ischemiareperfusion injury and reduce its toxicity. J Drug Target 2014; 22: 200-10.

16 Ma J, Dey M, Hui Y, Poulev A, Pouleva R, Dorn R, et al. Anti-inflammatory and immunosuppressive compounds from Tripterygium wilfordii. Phytochemistry 2007; 68: 1172-8.

17 Hikim AP, Lue YH, Wang C, Reutrakul V, Sangsuwan R, Swerdloff RS. Posttesticular antifertility action of triptolide in the male rat: evidence for severe impairment of cauda epididymal sperm ultrastructure. J Androl 2000; 21: 431-7.

18 He JK, Yu SD, Zhu HJ, Wu JC, Qin ZH. Triptolide inhibits NF-KB activation and reduces injury of donor lung induced by ischemia/reperfusion. Acta Pharmacol Sin 2007; 28: 1919-23.

19 Amal AA, Mary JK, Phillip G. Receptor-mediated endocytosis across human placenta: emphasis on megalin. Mol Pharm 2013; 10: 126978.

20 Gujral JS, Bucci TJ, Farhood A, Jaeschke H. Mechanism of cell death during warm hepatic ischemia-reperfusion in rats: apoptosis or necrosis? Hepatology 2001; 33: 397-405.

21 Cuzzocrea S, Riley DP, Caputi AP, Salvemini D. Antioxidant therapy: a new pharmacological approach in shock, inflammation, and ischemia/ reperfusion injury. Pharmacol Res 2001; 53: 135-59.

22 Granger DN, Kvietys PR. Reperfusion injury and reactive oxygen species: the evolution of a concept. Redox Biol 2015; 6: 524-51.

23 Chuanyu Li, Robert MJ. Reactive species mechanisms of cellular hypoxia-re oxygenation injury. Am J Physiol Cell Physiol 2002; 282: 227-41.

24 Senbel AM, Moneim LA, Omar AG. Celecoxib modulates nitric oxide and reactive oxygen species in kidney ischemia/reperfusion injury and rat aorta model of hypoxia/reoxygenation. Vasc Pharmacol 2014; 62: 24-31.

25 Vaidya VS, Ford GM, Waikar SS, Wang Y, Clement MB, Ramirez V, et al. A rapid urine test for early detection of kidney injury. Kidney Int 2009; 76: 108-14.

26 Takaharu I, Edwin JPA, Benjamin DH, Lakshman G, Jeremy SD, Bonventre JV. Kidney injury molecule-1 is a phosphatidylserine receptor that confers a phagocytic phenotype on epithelial cells. J Clin Invest 2008; 118: 1657-68.

27 Sung FL, Zhu TY, Au-Yeung KKW, Siow YL, Karmin O. Enhanced MCP1 expression during ischemia/reperfusion injury is mediated by 
oxidative stress and NF-kB. Kidney Int 2012; 62: 1160-70.

28 Dragun D, Tullius SG, Park JK, Maasch C, Lukitsch I, Lippoldt A, et al. ICAM-1 antisense oligodesoxynucleotides prevent reperfusion injury and enhance immediate graft function in renal transplantation. Kidney Int 1998; 54: 590-602.

29 Christian S, Jan H, Christian J, Christian B, Erik IC, Luft FC, et al. Megalin deficiency offers protection from renal aminoglycoside accumulation. J Biol Chem 2002; 277: 618-22.

30 Yuan ZX, Zhang ZR, Zhu D, Sun X, Gong T, Liu J, et al. Specific renal uptake of randomly $50 \% \mathrm{~N}$-acetylated low molecular weight chitosan. Mol Pharm 2009; 6: 305-14.

31 Lin Y, Li YP, Wang XH, Gong T, Zhang L, Sun X. Targeted drug delivery to renal proximal tubule epithelial cells mediated by 2-glucosamine. J Control Release 2013; 167: 148-56.

32 Jiang M, Dong Z. Regulation and pathological role of p53 in cisplatin nephrotoxicity. J Pharmacol Exp Ther 2008; 327: 300-7.

33 Price PM, Safirstein RL, Judit M. The cell cycle and acute kidney injury. Kidney Int 2009; 76: 604-13.

34 Yang L, Besschetnova TY, Brooks CR, Shah JV, Bonventre JV. Epithelial cell cycle arrest in $\mathrm{G}_{2} / \mathrm{M}$ mediates kidney fibrosis after injury. Nat Med 2010; 16: 535-44.

35 Manabu K, Sally K. Caspases and kinases in a death grip. Cell 2009; 138: 838-85.

36 Li XJY, Jiang ZZ, Zhang LY. Triptolide: progress on research in pharmacodynamics and toxicology. J Ethnopharmacol 2014; 155: 67-79.
37 Koo DDH, Fuggle SV. Impact of ischemia/reperfusion injury and early inflammatory responses in kidney transplantation. Transplant Rev 2000; 14: 210-24.

$38 \mathrm{Koo} \mathrm{DDH}$, Fuggle SV. Chemokines in ischemia/reperfusion injury. Curr Opin Organ Transplant 2002; 7: 100-6.

39 Qi M, Zheng LL, Qi Y, Han X, Xu YW, Xu L, et al. Dioscin attenuates renal ischemia/reperfusion injury by inhibiting the TLR4/MyD88 signaling pathway via up-regulation of HSP70. Pharmacol Res 2015; 100: 341-52.

40 Molitoris BA, Sutton TA. Endothelial injury and dysfunction: role in the extension phase of acute renal failure. Kidney Int 2004; 66: 496-9.

41 Ganesan R, Brian RW. TNF- $\alpha$ mediates chemokine and cytokine expression and renal injury in cisplatin nephrotoxicity. J Clin Invest 2002; 110: 835-42.

42 Nath KA, Norby SM. Reactive oxygen species and acute renal failure. Am J Med 2000; 109: 665-78.

43 Noiri E, Nakao A, Uchida K, Tsukahara H, Ohno M, Fujita T, et al. Oxidative and nitrosative stress in acute renal ischemia. Am J Physiol Renal Physiol 2001; 281: 948-57.

44 Dhalla NS Elmoselhi AB, Hatac TJ, Makino N. Status of myocardial antioxidants in ischemia-reperfusion injury. Cardiovasc Res 2000; 47: 446-56.

45 Kelly KJ, Williams WW, Colvin J, Meehan SM, Pringer TA, Ramos JCG, et al. Intercellular adhesion molecule-1-deficient mice are protected against ischemic renal injury. J Clin Invest 1996; 97: 1056-63. 